\title{
Analysis and Research about Standard Drafting Units based on Multidimensional Descriptive Statistics
}

\author{
Yunpeng Chen ${ }^{1, a^{*}}$, Ming Zhang ${ }^{2, b}$, Jingjing $\operatorname{Han}^{3, c}$ and Shiyuan Hong ${ }^{4, d}$ \\ ${ }^{1,2}$ Chinese Standardization Research Institute, Haidian, Beijing, China, 100191 \\ ${ }^{3,4}$ Communication University of China, Chaoyang, Beijing, China, 100024 \\ achenyp@cnis.gov.cn, bzhangming@cnis.gov.cn, chanjingjing24@126.com, \\ djocelynhung@qq.com
}

Keywords: Standardization; National standards; Drafting units; Statistics of standard category

\begin{abstract}
This article starts with solving problems on statistical analysis algorithm and tool study of standard drafting units. It shows the quantity relationship between standard drafting units and national standards by doing multidimensional descriptive statistics in terms of Standard Category, Establish and Revise Standards. Standard Property and so on, which helps readers understand Standardization better and helps relevant staff work on follow-up study. We write this paper in hopes that it can contribute to other statistical analysis of standard drafting units.
\end{abstract}

\section{Introduction}

Standards play an important role in cooperation and communication among countries all around the world. Standardization refers to the social practice, such as economy, technology, science and management, for the repetitive things and concepts, we establish, publish and implement standards to an agreement in order to obtain the best order and social benefits. This paper mainly focuses on the statistical analysis of the national standard and the standard drafting unit, which makes the data clearer and clearer, and helps to further statistical analysis in the future.

\section{Statistical objects and existing data}

These 1763 national standard details used in this paper come from 2016.There are data fields such as F_STD,national standard number and CCS, which can be expanded on the basis of existing data.First of all,we do descriptive statistics on existing standard categories in data field based on standard details.

According to standardized objects, national standards are classified into three categories: technical standards, management standards and work standards. The results are shown in the table:

Section Headings. The section headings are in boldface capital and lowercase letters. Second level headings are typed as part of the succeeding paragraph (like the subsection heading of this paragraph). 
Table 1 Relevant information of national standard categories

\begin{tabular}{|c|c|c|}
\hline $\begin{array}{l}\text { Standard } \\
\text { Categories }\end{array}$ & Explanation & Quantities \\
\hline Methods & Standards of product performance, quality inspection and test method . & 658 \\
\hline Products & $\begin{array}{l}\text { Technical requirements for product structure,specifications, quality and } \\
\text { inspection methods. }\end{array}$ & 575 \\
\hline Basics & $\begin{array}{c}\text { A standard that is the foundation of a range of other criteria and has } \\
\text { broad guiding significance. }\end{array}$ & 313 \\
\hline Management & $\begin{array}{l}\text { Standards made for management issues needing to be harmonized in } \\
\text { standardization. }\end{array}$ & 109 \\
\hline Safety & $\begin{array}{l}\text { To protect the safety of people and things,to protect the health of human } \\
\text { beings and protect the environment.Standards like this are generally } \\
\text { enforced. }\end{array}$ & 85 \\
\hline Health & $\begin{array}{l}\text { It specifies the hygienic allowable limit value of chemical,physical and } \\
\text { biological harmful factors in the production and living environment } \\
\text { according to health requirements. }\end{array}$ & 3 \\
\hline Environmental & $\begin{array}{l}\text { Based on the local fuel standards, it is mainly aimed at improving the } \\
\text { quality of human air and the environmental protection standards for high } \\
\text { oil prices and serious air pollution in urban areas. } \\
\text { Standards of responsibility,rights,scope,quality }\end{array}$ & 17 \\
\hline Others & $\begin{array}{l}\text { requirements,procedures, effects,inspection methods and assessment } \\
\text { methods of the work. }\end{array}$ & 3 \\
\hline
\end{tabular}

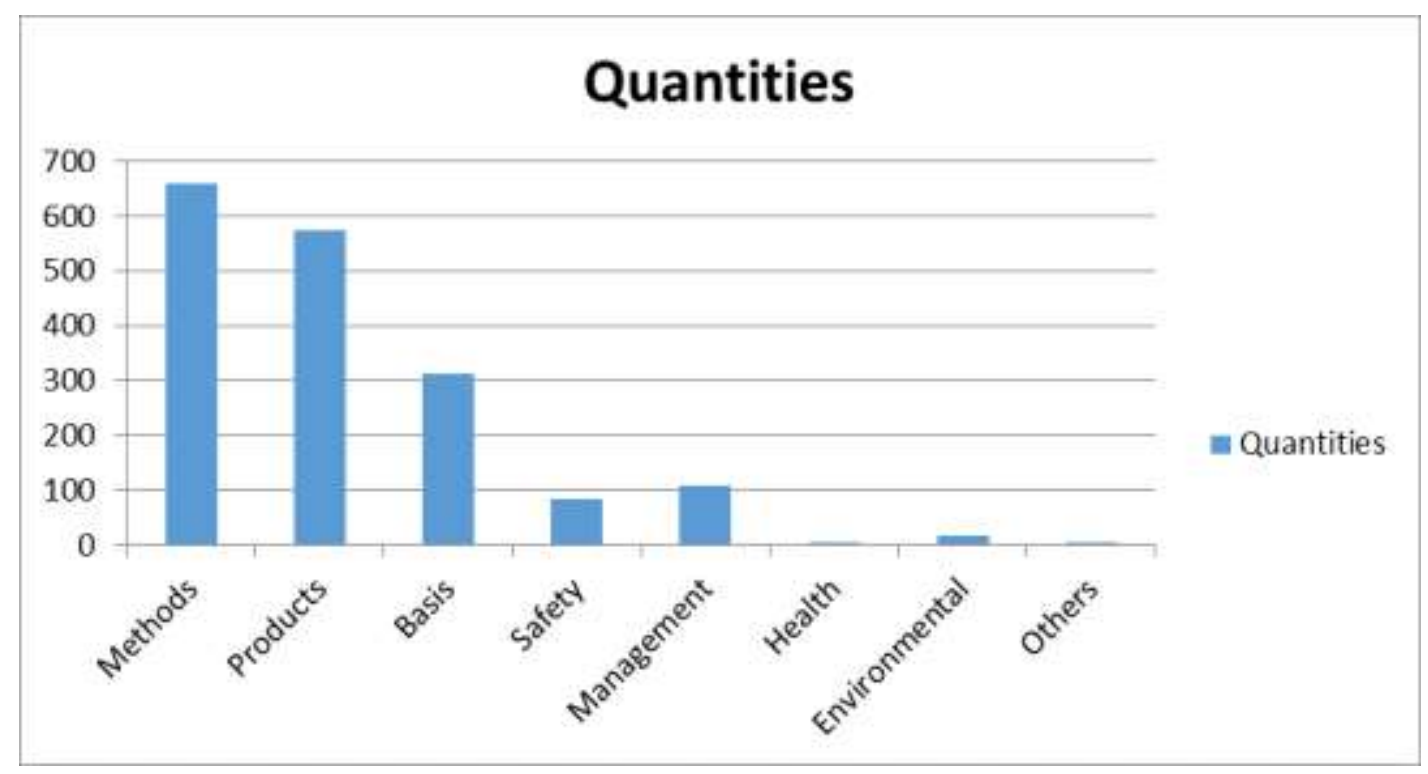

Figure 1. Quantities of each national standard categories

We can draw a conclusion after series of SPSS work: The standard that contains the most national standard details is Methods standard. It contains 658 details in all. On the contrary, Health standard and Others contains three details respectively, which are the least. Each category contains 220.38 national standard details on average, and the bar chart shows that most of the standard categories contain less than the average level.

From the above we can know that the number of different standard categories varies, and the standard category should be distinguished by statistical analysis of the standard drafting unit. 


\section{Perform descriptive statistical analysis when the object is the standard drafting unit}

Rank Statistical Analysis. Analyze the rank of the standard drafting unit and calculate the number of national standards drafted by each drafting unit. There are 1763 national standards published in 2016, which involve 5475 drafting units. The standard drafting unit has 11195 members in all, and every national standard was decided by 6.34 drafting units on average.

Now we select 20 standard drafting units including CMSI, CESI and China Productivity Center to do descriptive statistical analysis.

\section{Standard Category Statistics.}

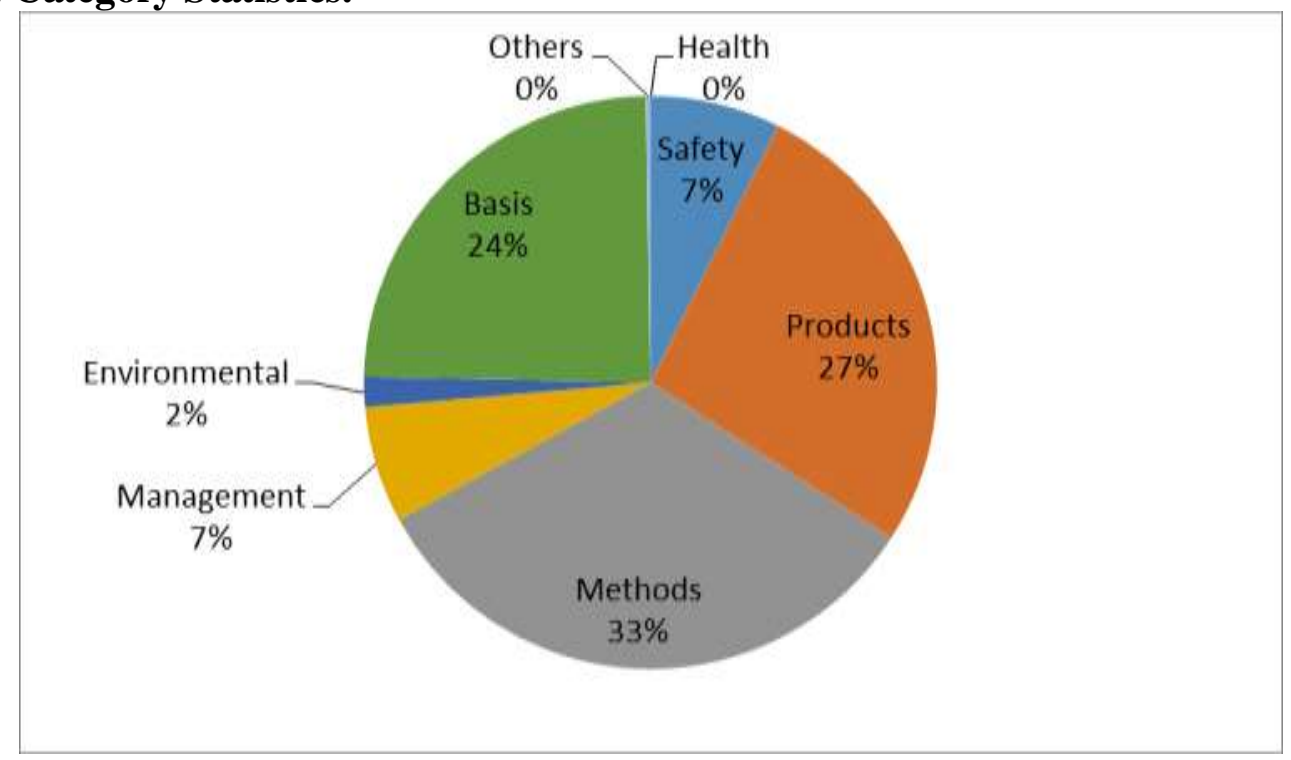

Figure 2. Output results of descriptive statistical analysis on standard categories

There are 1763 national standards published in 2016, according to the category, top 3 in the area of quantities are Methods standard (33\%), Products standard (27\%) and Basis standard (24\%), and the rest are Management standard, Safety standard, Environmental standard, Health standard and Others.

Table 2 Data of descriptive statistical analysis

\begin{tabular}{|c|c|c|c|c|c|}
\hline & $\mathrm{N}$ & minimum & maximum & mean & Std. \\
\hline Safety & 10 & 1 & 18 & 5.60 & 6.275 \\
Products & 18 & 1 & 46 & 11.33 & 12.756 \\
Methods & 19 & 5 & 65 & 13.21 & 13.164 \\
Management & 10 & 1 & 22 & 5.00 & 6.464 \\
Environmental & 5 & 1 & 5 & 2.60 & 1.673 \\
Basis & 16 & 1 & 54 & 11.63 & 13.421 \\
Others & 1 & 2 & 2 & 2.00 & $\cdot$ \\
Health & 0 & & & & \\
effective N & 0 & & & & \\
(listwise) & 0 & & & & \\
\hline
\end{tabular}

As shown in the pictures above, we can know that the standard of method class involves 19 drafting units, and the average drafting unit drafts 13.21 standards in the method category.Products standard involves 18 drafting units, and the average drafting unit drafts 11.33 products standards.Basis standard involves 16 drafting units in all, and every unit drafts 11.63 basis standards.

Health standards are generally drafted by multiple units, but this character wasn't reflected in the data we have selected. Each drafting unit drafts 2.6 Environmental standards and 2 standards in the Others category on average. As for the rest of the standards, the average drafting unit drafts about 5 of them. 


\section{Standard Property Statistics.}

Table 3 Information of descriptive statistics

\begin{tabular}{|c|c|c|c|c|c|}
\hline & $\mathrm{N}$ & minimum & maximum & mean & Std. \\
\hline $\begin{array}{c}\text { Mandatory } \\
\text { national } \\
\text { standards }\end{array}$ & 20 & 0 & 4 & .25 & .910 \\
$\begin{array}{c}\text { Recommended } \\
\text { national } \\
\text { standards } \\
\text { Instructional } \\
\text { technical } \\
\text { documents } \\
\text { effective N } \\
\text { (listwise) }\end{array}$ & 20 & 13 & 128 & 36.60 & 30.301 \\
\hline
\end{tabular}

Units draft mandatory national standards are rare. China Automotive Research Center drafted 4 standards, which is the biggest number. Each drafting unit drafts 0.25 national standards on average. Most of the drafting units participated in drafting the recommended national standards, and the average unit involved in drafting 36.6 standards. Every standard drafting unit drafts 1.25 Instructional technical documents approximately.

\section{Establish and Revise Standards Statistics.}

The darfting unit was basically involved in establishing and revising standards. There are 237 standards established and 525 standards revised in the data we have selected.Each drafting unit participated in establishing 13.17 standards and revising 26.25 standards on average.

\section{The Cooperation Unit Statistics.}

Analyze the relationship between standard drafting units and calculate the distance (similarity) between standard drafting units. We use $\alpha$ express the number of standards drafted by unit 1 and 2 together, and use $\beta$ express the number of standards drafted by unit $1 *$ the number of standards drafted by unit2. Here, we can refer to the concept of cosine Similarity and Pearson Similarity.

$$
\operatorname{sim}=\frac{\alpha}{\beta}
$$

\section{Conclusion}

According to the definition of standard, it's a kind of specification and document which was agreed upon by consensus. From the perspective of standardization, with the development of economy, society, science and technology and international trade, we can see that the standard do a greater job in planning, and it becomes an increasingly important means of governance. According to descriptive statistical analysis of standard drafting units in the article,we know that national standards relate to all aspects of different industries. And the procedure of standard drafting needs to be recognized and agreed by multiple units. To achieve standardization better,all units need to work together to perfect the role of different departments in the formulation,implementation and supervision of standards in various areas.

\section{Acknowledgement}

This research was financially supported by the Data Acquisition and Applicability of Application Technology of Brand Evaluation and National Standard Research (252016z-4623-01). 


\section{References}

[1] Information on https://wenku.baidu.com/view/881ad177f61fb7360a4c655a.html

[2] S.J. Liu, H. Liu: China Soft Science, Vol. 7 (2015), p. 1002-9753.

[3] National Standardization System Construction and Development Plan (2016 2020). Machinery Industry Standardization \& Quality, Vol. (2016) No.3, p.1007-6905.

[4] China's National Environmental Protection Standard Breached 1,100 items. The standard and quality of light industry, Vol. (2009) No.2, p.1004-4108.

[5] W.J. Zhu, C.H Xie, S.G. Wang: China J Health Lab Technol, Vol. (2011) No.12, p.1004-8685.

[6] The First Batch of 259 Health National Standards Was Issued. Chinese Journal of Industrial Medicine, Vol. (1996) No.4, p.1002-221X.

[7] S.Q. Zhang: World Standardization and Quality Management, Vol. (2007) No.10, p.1002-610X.

[8] P. Wang: China Standardization, Vol. (2012) No.5, p.1002-5944.

[9] The Ministry of Environmental Protection Issued the 13th Five-year Plan for Environmental Protection. Paper and Paper Making, Vol. (2017) No.3, p.1001-6309.

[10] J.S. Zhang, Z. Zhang, Y. Wang: Conference Proceedings of the China Standardization Association (September 25-26, 2014). P. 178-183. 